\title{
Consumo por idosos nos arranjos familiares "unipessoal" e "residindo com o cônjuge": uma análise por regiões do país, a partir de dados da POF (2008/2009)
}

\author{
Consumption by the elderly in "unipersonal" and "living with a spouse" family arrangements: an \\ analysis per regions in the country, from POF data (2008/2009)
}

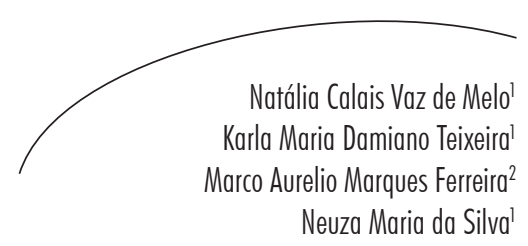

Resumo

Objetivo: Identificar e comparar, com base nos microdados da Pesquisa de Orçamentos Familiares POF/IBGE (2008/2009), os tipos de bens e serviços que os idosos dos arranjos familiares "unipessoal" e "residindo com o cônjuge" consomem nas diversas regiões do país. Métodos: Estudo descritivo, quantitativo, com corte transversal, que utilizou os microdados da POF/IBGE (2008/2009), utilizando variáveis sociodemográficas e bens e serviços consumidos pelos idosos dos dois arranjos supracitados. Os dados foram extraídos utilizando-se o software STATA e analisados estatisticamente por meio do SPSS. Resultados: Em ambos os arranjos familiares pesquisados, os maiores gastos em relação às categorias de despesas analisadas eram dos idosos que residiam com o cônjuge e moravam na Região Sul do país. A renda total do domicílio foi o fator que teve maior influência no consumo de bens e serviços entre os arranjos familiares. Conclusão: Em ambos os arranjos familiares estudados, os residentes na Região Sul apresentaram os maiores gastos, uma vez que apresentaram maior renda. Logo, verifica-se que a desigualdade na distribuição da renda no país é fator que influencia no consumo de bens e serviços, uma vez que a renda está diretamente relacionada ao poder de compra.

Abstract

Objective: To identify and to compare, based on microdata from POF/IBGE (2008/2009), the types of goods and services consumed by the elderly of "unipersonal" families and "residing with the spouse" in the different regions in the country. Methods: Descriptive, quantitative and transversal study that used microdata of POF/IBGE (2008/2009) using social-demographic variables and goods and services consumed by the elderly of the two previously mentioned arrangements. Data were extracted using STATA software and statistically analyzed using SPSS. Results: The highest expenses in relation

Palavras-chave: Idoso. Características da Família. Estado. Envelhecimento da População.

Key words: Elderly. Family Characteristics. State. Population Aging.

Departamento de Economia Doméstica. Universidade Federal de Viçosa. Viçosa, MG, Brasil.

Departamento de Administração e Contabilidade. Universidade Federal de Viçosa. Viçosa, MG, Brasil.

Este artigo é proveniente da dissertação de mestrado intitulada "Consumo por idosos em arranjos familiares 'unipessoal' e 'residindo com o cônjuge': análise de dados da POF 2008/2009”, apresentada pela primeira autora ao Programa de Pós-graduação em Economia Doméstica da Universidade Federal de Viçosa, Viçosa-MG, Brasil. 
to expenditure categories analyzed were for the elderly who lived with their spouse and lived in the Southern Region of the country in both family arrangements studied. Total household income was the factor that had the greatest influence on the consumption of goods and services among family arrangements. Conclusion: In both family arrangements members studied, those who resided in the Southern Region are those with the biggest spending, once presented higher income. Soon, one realizes that unequal distribution of income in the country is a factor that influences the consumption of goods and services, since income is directly related to purchasing power.

\section{INTRODUÇÃO}

Uma das transformações sociais mais importantes que ocorreram está relacionada ao aumento demográfico dosidosos, sendo crescente o fenômeno do envelhecimento da população em todas as sociedades economicamente desenvolvidas ou em desenvolvimento. ${ }^{1}$

O envelhecimento populacional no Brasil, assim como em vários outros países em desenvolvimento, ocorre num contexto socioeconômico desfavorável, devido a baixas taxas de crescimento econômico, elevados níveis de desigualdade social, altas taxas de analfabetismo, carência de instituições devidamente consolidadas, entre outros. ${ }^{2}$

Há de se ressaltar, porém, que no Brasil,${ }^{3,4} \mathrm{com}$ a estabilização econômica proporcionada pelo Plano Real, houve aumento do poder aquisitivo e do bem-estar das famílias. Com essas mudanças econômicas, o padrão de consumo se modificou, havendo mudanças nas estruturas dos gastos e dos rendimentos das famílias, já que os gastos estão relacionados a alguns fatores, destacandose as alterações e distribuições da renda, além dos preços dos produtos. Tais modificações também estão sendo vivenciadas pelos idosos.

O idoso contemporâneo, da segunda década do século XXI, tem acesso a uma renda maior em relação às últimas décadas. No período de 1992 a 2010, a renda média dos idosos foi a que mais cresceu, saltando de $\mathrm{R} \$$ 660,00 em 1992 para $\mathrm{R} \$$ 1.092,00 em 2009. ${ }^{5}$ Esse aumento e seu maior poder de compra fizeram com que ele se tornasse um grupo social que atrai o interesse individual e coletivo dos industriais, de forma crescente. ${ }^{1}$

No entanto, as empresas estão se preocupando pouco com esse novo público que está surgindo, não atentando para o fato de que este é um grupo que está em constante crescimento e que deveria ser visto como consumidor em potencial, principalmente devido a seu poder aquisitivo, disponibilidade de tempo e preocupação com sua saúde e bem-estar. ${ }^{6,7}$ Alguns autores afirmam que as empresas instaladas no Brasil nunca prestaram tanta atenção nos idosos como em 2011, pois nos últimos 19 anos esse segmento da população cresceu não só em número, mas em poder de consumo, uma vez que eles compram, viajam, vão ao cinema, frequentam clubes da terceira idade, ajudam a família, namoram, casam-se outra vez e têm uma saúde melhor do que no fim da década de $1990 .^{5}$

Nesse sentido, o envelhecimento populacional trará impactos significativos para diversos setores, uma vez que este segmento da população possui demandas próprias, pois grande parcela tem vida economicamente ativa e está preocupada em viver mais e melhor. Assim sendo, todo bem ou serviço que possa contribuir para uma melhor qualidade de vida desse segmento tem um mercado potencial bastante elevado. ${ }^{8}$

É importante ressaltar, ainda, que à medida que se envelhece, as preferências e necessidades por produtos e serviços tendem a mudar. As necessidades e gastos de uma família são afetados por fatores como o número de pessoas na família, sua idade e o número de adultos que trabalham 
fora. Reconhecendo que as necessidades e gastos familiares mudam com o tempo, faz-se necessário destacar o ciclo de vida familiar, que combina tendências na composição da renda e da família com as mudanças nas demandas colocadas para essa renda, ${ }^{9}$ como é o caso dos idosos.

A mudança na condição do idoso na família, proporcionada pelo melhor acesso à renda, à longevidade e saúde, se expressa na independência dos idosos em relação à família, uma vez que eles podem, ao mesmo tempo, ser fonte de ajuda, como também serem capazes de morar sozinhos ou apenas com seus cônjuges, o que tem possibilitado redefinir sua participação na vida ativa das famílias. ${ }^{10}$

O envelhecimento populacional para vários países, com contextos sociais distintos, traz mudanças importantes na dinâmica das famílias. ${ }^{11}$ Assim, há distintos modelos de famílias, caracterizando-se, mais do que nunca, pela diversidade dos arranjos, que variam de acordo com as características pessoais, familiares e culturais. ${ }^{12}$ Cada tipo de arranjo familiar apresenta desafios tanto para o idoso quanto para seus familiares e para a comunidade que os abrange. ${ }^{13}$

Com sua maior longevidade, maior poder aquisitivo e exposição constante às propagandas e estereótipos impostos pela sociedade, os idosos buscam produtos e serviços para satisfazer não só suas necessidades, mas também sua vaidade. Assim, não obstante as reflexões já desempenhadas sobre a questão do consumo efetivado por idosos no país, são importantes as análises no sentido de compreender a dimensão do envelhecimento em termos do consumo, haja vista que com o aumento da população idosa, novas demandas vêm surgindo para atender e assegurar a qualidade de vida desse segmento.

Diante do exposto objetivou-se, com este estudo, identificar e comparar, com base nos microdados da Pesquisa de Orçamentos Familiares (2008/2009), ${ }^{14}$ os tipos de bens e serviços que os idosos dos arranjos familiares "unipessoal" e "residindo com o cônjuge" consomem, nas diversas regiões do país.

\section{METODOLOGIA}

A pesquisa teve caráter quantitativo, descritivo, com corte transversal, e utilizou dados secundários. Os dados foram extraídos dos microdados da POF $(2008 / 2009),{ }^{14}$ realizada pelo Instituto Brasileiro de Geografia e Estatística (IBGE). A opção por trabalhar com esses dados se deve ao fato de ser uma pesquisa representativa em nível nacional sobre orçamento doméstico.

Os dados da POF $(2008 / 2009)^{14}$ visam, principalmente, mensurar as estruturas de consumo, dos gastos e dos rendimentos das famílias, uma vez que inclui perguntas detalhadas sobre as duas medidas de bem-estar: consumo e renda.

A amostra da POF $(2008 / 2009)^{14}$ abrangeu ao todo 55.970 domicílios, representando aproximadamente $0,1 \%$ do total de domicílios do país. Para a expansão da amostra, cada domicílio representou um número de domicílios particulares permanentes da população. Para tanto, cada domić́lio apresentou um fator de expansão, que permitiu obter as estimativas das variáveis da pesquisa para todo o universo. Mais detalhes sobre a seleção da amostra podem ser encontrados na documentação da base de dados. ${ }^{15}$

Para atingir o objetivo proposto, o universo de análise foram os arranjos familiares de idosos que constituíam unidades domésticas unipessoais ou que residiam com o cônjuge em todas as regiões do país e que foram pesquisados pela POF (2008/2009). ${ }^{14}$ Para conduzir o estudo, foram considerados "idosos" todos os indivíduos de 60 anos de idade ou mais. ${ }^{16}$

Inicialmente, os dados foram extraídos dos microdados da POF $(2008 / 2009)^{14}$ utilizando o software STATA (Data Analysis and Statistical Software), totalizando 55.970 domicílios de todo o país. A extração desse volume de dados se deu pelo fato de os domicílios serem constituídos de diversas pessoas, configurando os diferentes arranjos familiares. Como o universo de análise que o estudo propôs era o "arranjo familiar unipessoal" (AFU) e o "arranjo familiar 
residindo com o cônjuge" (AFRC), no qual o idoso era o chefe do domicílio, a amostra foi constituída por 2.532 domicílios com idosos que moravam sozinhos e 2.619 domicílios com idosos que residiam com o cônjuge, totalizando 5.151 domicílios, representando $9,20 \%$ do total de domicílios pesquisados pela POF. ${ }^{14}$

Entretanto, ao realizar análise exploratória dos dados, constatou-se que havia alguns valores atípicos. Contudo, como se trata de pesquisa de caráter quantitativo, em que muitas das técnicas estatísticas envolvem cálculo de média e a média é sensível a valores extremos, optou-se por retirar 19,2\% dos domicílios que apresentavam tais valores, visto que alguns destes não apresentavam nenhum valor registrado com gastos de consumo e o restante possuía valores discrepantes (outliers). Logo, a amostra contou com 4.162 domicílios, sendo que 2.160 (51,9\%) tinham apenas idosos morando sozinhos e 2.002 (48,1\%), com o cônjuge.

A partir da extração dos dados em valores desagregados, optou-se por importá-los para o software SPSS 20.0 (StatisticalPackage for Social Sciences). Para comparar o consumo de bens e serviços de acordo com o tipo de arranjo familiar, foi utilizado um teste $t$ para amostras independentes. Este pode ser usado para testar uma hipótese que estabelece que as médias das variáveis associadas com duas amostras ou grupos independentes serão iguais, avaliando se as diferenças observadas entre as médias de duas amostras ocorreram por acaso ou se houve diferença verdadeira. ${ }^{17}$

No caso em estudo, para comparar quais bens e/ou serviços que os dois grupos de idosos consumiam, procedeu-se ao teste $t$ Student para igualdade de médias em amostras independentes. Para sua execução, partiu-se da hipótese nula de que não havia distinção do consumo em razão do arranjo familiar, sendo a hipótese alternativa, se o contrário ocorresse, ou seja, que houvesse diferença no consumo em razão do arranjo familiar. Posteriormente, foi realizada análise de variância que é um método para testar a igualdade de três ou mais médias populacionais ${ }^{18}$ e que verifica se determinados fatores produzem mudanças sistemáticas em algumas variáveis relevantes no estudo. ${ }^{19}$ Assim sendo, foi possível verificar se o consumo por idosos nos arranjos familiares estudados se diferenciava de acordo com o local de residência.

A partir das informações geradas, os dados foram descritos, analisados e confrontados com a fundamentação teórica.

Segundo o Comitê de Ética em Pesquisa da Universidade Federal de Viçosa, uma vez que os dados, embora relativos a seres humanos, eram procedentes de banco de dados de uso e acesso público, não houve necessidade do projeto ser submetido a sua aprovação.

\section{RESULTADOS E DISCUSSÃO}

No que se refere à localização geográfica dos idosos pesquisados pela POF (2008/2009), ${ }^{14}$ a maioria daqueles que moravam sozinhos estava na Região Nordeste do país ( $\mathrm{n}=682 ; 31,6 \%) ; 30,3 \%$ $(\mathrm{n}=654)$ no Sudeste; $14,6 \%(\mathrm{n}=316)$ no CentroOeste; $14 \%(n=302)$ no Sul; e 9,5\% $(n=206)$ no Norte. Já os idosos que residiam com o cônjuge, a maioria estava na Região Sudeste ( $\mathrm{n}=611$; $30,5 \%) ; 28 \%(\mathrm{n}=560)$ residiam no Nordeste; $17,8 \%$ ( $n=357)$, no Centro-Oeste; $16,4 \%$ ( $n=328)$, no Sul; e 7,3\% ( $n=146)$, no Norte. Do total de idosos pesquisados, do AFU e AFRC, 79,1\% $(\mathrm{n}=1.709)$ e $67,1 \% \quad(\mathrm{n}=1.344)$, respectivamente, residiam na área urbana ${ }^{20}$ do país, tendência que pode ser explicada pelo fato de buscarem, nessas áreas, melhores condições de vida e atendimento às suas necessidades.

Analisando em separado as despesas dos AFUs e AFRCs, no que se refere aos itens de despesa com habitação, despesas diversas, lazer, transporte, alimentação em domicílio, fumo, produtos de higiene e cuidados pessoais, assistência à saúde e vestuário, as diferenças observadas nos dois arranjos familiares para todos esses itens de despesas foram estatisticamente significativas $(p<0,05)$, conforme pode ser visualizado na tabela 1. 
Rejeita-se com 95\% de confiança $(\mathrm{p}<0,05)$ a hipótese de não haver diferença entre $\mathrm{o}$ consumo em razão do arranjo familiar, visto que, observando-se as médias de ambos os grupos, em todos os itens de despesas admite-se que o AFRC gastava mais do que o AFU.

Quanto ao item de despesa com educação, a diferença de $-1,58$ observada na tabela 1 entre os dois grupos não foi estatisticamente significativa (sig=0,327, $\mathrm{p}>0,05)$. Nota-se que o intervalo de confiança a $95 \%$, podendo variar de $-8,32$ a 5,15 para a diferença das médias, inclui o zero, o que corrobora a conclusão de não rejeição da igualdade de médias, ou seja, ambos os arranjos familiares gastam igualmente no que se refere ao item "educação". Como a variável "educação" foi constituída pela soma das variáveis "despesas com livros e revistas" e "outros cursos e/ou atividades", optou-se por fazer o teste tentre estas variáveis também para ver se existia diferença de consumo entre os dois arranjos familiares. $\mathrm{O}$ referido teste, porém, confirmou a igualdade de média entre elas.

No que concerne ao consumo de alimentos fora do domicílio, verifica-se que a diferença de -46,20 observada na tabela 1 nos dois grupos também não foi estatisticamente significativa (sig $=0,088, \mathrm{p}>0,05)$. Os intervalos de confiança a 95\%, podendo variar de $-99,26$ a 6,86 para a diferença das médias, incluíram o zero, o que contribui para a não rejeição da igualdade de médias, ou seja, infere-se que ambos os arranjos gastavam igualmente no que se refere à alimentação fora do domicílio.

Tabela 1. Teste tpara os itens de despesas consumidos pelos idosos nos arranjos familiares "unipessoal" e "residindo com o cônjuge". Brasil, 2008/2009.

\begin{tabular}{lccccc}
\hline \multicolumn{1}{c}{ Variáveis } & $\begin{array}{c}\text { Diferença de médias } \\
\text { entre os arranjos } \\
\text { (AFRC - AFU) }\end{array}$ & $\begin{array}{c}\text { Intervalo de confiança } \\
(\mathrm{IC}-95 \%)\end{array}$ & $t$ & Sig. \\
\hline Habitação & 651,69 & 510,76 & 792,62 & 9,06 & $0,000^{*}$ \\
Despesas diversas & 85,06 & 14,73 & 155,40 & 2,37 & $0,018^{*}$ \\
Lazer & 46,37 & 21,34 & 71,40 & 3,632 & $0,000^{*}$ \\
Transporte & 908,56 & 783,24 & $1.033,88$ & 14,215 & $0,000^{*}$ \\
Educação & $-1,58$ & $-8,32$ & 5,15 & $-0,460$ & 0,645 \\
Livros e revistas & $-3,57$ & $-8,18$ & 1,03 & $-1,54$ & 0,123 \\
Outros cursos & 1,99 & $-2,84$ & 6,83 & 0,808 & 0,419 \\
Alimentação em domicílio & 758,52 & 595,68 & 921,36 & 9,133 & $0,000^{*}$ \\
Alimentação fora do domicílio & $-46,20$ & $-99,26$ & 6,86 & $-1,707$ & 0,088 \\
Fumo & 35,24 & 18,53 & 51,96 & 4,13 & $0,000^{*}$ \\
Higiene e cuidados pessoais & 67,16 & 28,65 & 105,66 & 3,420 & $0,001^{*}$ \\
Assistência à saúde & 772,53 & 628,86 & 916,20 & 10,54 & $0,000^{*}$ \\
Vestuário & 164,48 & 127,68 & 201,27 & 8,764 & $0,000^{*}$ \\
\hline
\end{tabular}

$\mathrm{AFRC}=$ arranjo familiar residindo com o cônjuge; $\mathrm{AFU}=$ arranjo familiar unipessoal; $*$ Significativo ao $\mathrm{p}<0,05$. 
Entretanto, foi possível verificar que o AFRC gastava estatisticamente mais do que o AFU no que se refere aos itens: despesas com habitação, despesas diversas, lazer, transporte, alimentação em domicílio, fumo, produtos de higiene e cuidados pessoais, assistência à saúde e vestuário. Este aumento pode estar associado à composição familiar, uma vez que o número de membros do AFRC é o dobro do AFU.

Foi possível afirmar que ambos os arranjos gastavam estatisticamente o mesmo valor com educação e alimentação fora do domicílio, o que mostra que os idosos, independentemente do arranjo familiar, estão preocupados em viver mais e melhor. Sabe-se que cada vez mais os idosos estão preocupados com a sua qualidade de vida e o envelhecimento já traz consigo perdas do potencial biológico. ${ }^{8,21}$ Entretanto, se faz necessário considerar a influência, entre outras variáveis, dos hábitos alimentares, uma vez que eles podem interferir na qualidade de vida dos idosos e, assim, gerar um perfil diferenciado do envelhecimento biológico. Além disso, a educação pode melhorar os processos cognitivos, motores, sensorial e intelectual deste segmento da população.

Com o intuito de comparar se existia diferença entre os tipos de bens e serviços que os idosos dos AFUs e AFRCs consumiam nas diversas regiões do país, as variáveis "despesa com habitação", "despesas diversas", "lazer", "transporte", "educação", "alimentação", "fumo", "higiene e cuidados pessoais", "assistência à saúde" e "vestuário" foram submetidas à análise de variância.

Pelo teste F da ANOVA, foi possível inferir que para o AFU existia diferença nas despesas com habitação $(\mathrm{p}=0,000)$, despesas diversas $(p=0,000)$, lazer $(p=0,001)$, transporte $(\mathrm{p}=0,000)$, educação $(\mathrm{p}=0,024)$, alimentação fora do domicílio $(\mathrm{p}=0,001)$, assistência à saúde $(\mathrm{p}=0,000)$ e vestuário $(\mathrm{p}=0,001)$ em relação às regiões do país. Já em relação ao AFRC, os itens de despesas que tiveram diferença, quando comparados com as regiões do país, foram habitação $(p=0,000)$, despesas diversas $(p=0,000)$, lazer $(p=0,000)$, transporte $(\mathrm{p}=0,000), \quad$ alimentação em domicílio $(\mathrm{p}=0,001)$, assistência à saúde $(\mathrm{p}=0,000)$ e vestuário $(p=0,000)$. Entretanto, os itens que possuíam uma média de gasto igual $(\mathrm{p}>0,05)$ entre as regiões do país foram: alimentação em domicílio para o AFU; educação e alimentação fora do domić́lio no AFRC; e fumo e produtos de higiene e cuidados pessoais, em ambos os arranjos, conforme pode ser verificado nas tabelas 2 e 3 . 
Tabela 2. Média dos gastos, por região, das categorias de despesas do arranjo familiar unipessoal. Brasil, 2008/2009.

\begin{tabular}{lcccccc}
\hline \multicolumn{1}{c}{ Variáveis } & $\begin{array}{c}\text { Norte } \\
(\mathrm{R} \$)\end{array}$ & $\begin{array}{c}\text { Nordeste } \\
(\mathrm{R} \$)\end{array}$ & $\begin{array}{c}\text { Sudeste } \\
(\mathrm{R} \$)\end{array}$ & $\begin{array}{c}\text { Sul } \\
(\mathrm{R} \$)\end{array}$ & $\begin{array}{c}\text { Centro-Oeste } \\
(\mathrm{R} \$)\end{array}$ & $\mathrm{p}$ \\
\hline Habitação & $1.914,22$ & $1.530,21$ & $2.235,67$ & $2.282,35$ & $1.854,57$ & $0,000^{*}$ \\
Despesas diversas & 283,21 & 360,06 & 566,05 & 587,11 & 350,42 & $0,000^{*}$ \\
Lazer & 105,89 & 73,43 & 162,58 & 173,10 & 134,99 & $0,001^{*}$ \\
Transporte & 593,75 & 367,38 & 448,43 & 657,13 & 789,09 & $0,000^{*}$ \\
Educação & 2,98 & 5,72 & 15,70 & 29,56 & 14,77 & $0,024^{*}$ \\
Alimentação em domicílio & $1.819,17$ & $1.751,60$ & $1.930,41$ & $1.871,12$ & $1.661,51$ & 0,459 \\
Alimentação fora domicílio & 302,53 & 230,03 & 449,66 & 288,41 & 337,46 & $0,001 *$ \\
Fumo & 57,32 & 48,09 & 47,43 & 71,50 & 46,13 & 0,507 \\
Higiene e cuidados pessoais & 164,27 & 130,51 & 153,14 & 125,86 & 132,65 & 0,739 \\
Assistência à saúde & 575,95 & 936,69 & $1.596,54$ & $1.762,50$ & $1.206,99$ & $0,000^{*}$ \\
Vestuário & 263,45 & 258,65 & 360,85 & 389,61 & 317,16 & $0,001 *$ \\
\hline
\end{tabular}

$\mathrm{p}=$ nível de significância.

*Significativo ao $\mathrm{p}<0,05$.

Tabela 3. Média dos gastos, por região, das categorias de despesas do arranjo familiar residindo com o cônjuge. Brasil, 2008/2009.

\begin{tabular}{lcccccc}
\hline \multicolumn{1}{c}{ Variáveis } & $\begin{array}{c}\text { Norte } \\
(\mathrm{R} \$)\end{array}$ & $\begin{array}{c}\text { Nordeste } \\
(\mathrm{R} \$)\end{array}$ & $\begin{array}{c}\text { Sudeste } \\
(\mathrm{R} \$)\end{array}$ & $\begin{array}{c}\text { Sul } \\
(\mathrm{R} \$)\end{array}$ & $\begin{array}{c}\text { Centro-Oeste } \\
(\mathrm{R} \$)\end{array}$ & $\mathrm{p}$ \\
\hline Habitação & $2.618,63$ & $2.019,45$ & $2.962,77$ & $2.805,94$ & $2.607,38$ & $0,000^{*}$ \\
Despesas diversas & 469,16 & 376,80 & 646,70 & 638,91 & 498,23 & $0,000^{*}$ \\
Lazer & 154,74 & 71,14 & 178,06 & 264,75 & 245,37 & $0,000^{*}$ \\
Transporte & $1.080,08$ & 921,54 & $1.641,10$ & $1.806,58$ & $1.625,67$ & $0,000^{*}$ \\
Educação & 13,03 & 12,75 & 10,96 & 5,74 & 15,59 & 0,810 \\
Alimentação em domicílio & $2.109,10$ & $2.368,57$ & $2.620,59$ & $3.115,66$ & $2.513,90$ & $0,001^{*}$ \\
Alimentação fora domicílio & 276,90 & 249,80 & 305,25 & 335,31 & 239,94 & 0,421 \\
Fumo & 111,92 & 66,50 & 89,93 & 122,20 & 71,28 & 0,088 \\
Higiene e cuidados pessoais & 168,49 & 204,05 & 234,84 & 195,41 & 192,32 & 0,851 \\
Assistência à saúde & $1.488,42$ & $1.598,70$ & $2.526,80$ & $2.027,07$ & $2.072,57$ & $0,000^{*}$ \\
Vestuário & 433,90 & 390,70 & 500,60 & 629,03 & 473,29 & $0,000^{*}$ \\
\hline
\end{tabular}

$\mathrm{p}=$ nível de significância.

$*$ Significativo ao $\mathrm{p}<0,05$. 
A diferença de gastos entre os itens de consumo considerados e as regiões do país ocorre provavelmente devido à distribuição desigual de renda entre as regiões, uma vez que, nos dois arranjos familiares estudados, a maioria daqueles que pertencia à faixa $\mathrm{AB}$ de renda (considerando a renda total superior a $\mathrm{R} \$ 4.591,01)$ residia no Sudeste do país, sendo 39,5\% ( $\mathrm{n}=17)$ do AFU e $43,1 \%(\mathrm{n}=25)$ do AFRC. Além do fator "renda", alguns autores" consideram que os padrões de consumo podem ser moldados pelo clima, por influências culturais e recursos únicos, além das diferenças regionais que exercem grande impacto sobre os estilos de vida dos consumidores porque muitas de nossas preferências são ditadas pelos costumes e disponibilidades locais.

Por meio dos testes post hoc, é possível afirmar que os gastos com habitação dos idosos do AFU que residiam nas regiões Sudeste e Sul eram, respectivamente, $\mathrm{R} \$ 705,45$ e $\mathrm{R} \$ 752,13$ a mais do que os da Região Nordeste. E já em relação ao AFRC, os gastos desse arranjo da Região Nordeste se diferenciaram estatisticamente das regiões Sudeste, Sul e Centro-Oeste. Estas possuíam um gasto de $\mathrm{R} \$ 943,31, \mathrm{R} \$ 786,47, \mathrm{R} \$$ 587,92 , respectivamente, a mais com habitação do que a Região Nordeste do país. Assim, é possível afirmar que o AFRC gastava mais com habitação do que o AFU, e que ambos os arranjos residentes nas regiões Sul e Sudeste gastavam mais do que os que residiam no Nordeste do país. A composição familiar pode ter influenciado nesse resultado, pois como nos gastos com habitação estão inclusos os gastos com energia, água, entre outros, quanto mais pessoas residirem no domicílio, maiores serão as despesas com estes itens.

Os resultados encontrados corroboram outras pesquisas nacionais, que mostram que as despesas com habitação respondem pela maior participação nas despesas monetária e não monetária de consumo das famílias, tanto em nível nacional como regional. ${ }^{15}$

No que se refere aos gastos com despesas diversas, em relação ao AFU, foi possível inferir que aqueles que residiam na Região Sudeste gastavam $\mathrm{R} \$ 282,84$ e no Sul, $\mathrm{R} \$ 303,89$ a mais do que os que moravam no Norte, e essas mesmas regiões gastavam $\mathrm{R} \$ 205,99$ e $\mathrm{R} \$ 227,04$, respectivamente, a mais que o Nordeste. Com um nível de significância de 0,000 , foi possível aceitar as comparações dos gastos entre as regiões Sudeste, Sul e Nordeste para o AFRC. Os que residiam nas regiões Sudeste e Sul deste arranjo familiar gastavam, respectivamente, $\mathrm{R} \$ 269,90 \mathrm{e}$ $\mathrm{R} \$ 262,10$ a mais do que os da Região Nordeste. As regiões Norte e Centro-Oeste não apresentaram diferença estatisticamente significativa com despesas diversas em relação às outras regiões.

Constata-se, assim, que os idosos dos arranjos familiares estudados que residiam na Região Nordeste gastavam menos com despesas diversas do que os das regiões Sul e Sudeste do país, talvez pelo fato de a maioria dos idosos dessa região pertencer às menores faixas de renda (D e E). Assim, é provável que estivessem menos preocupados com gastos supérfluos, alguns dos quais compõem a variável "despesas diversas", como doações, animais de estimação, jogos, entre outros.

Os gastos com lazer do AFU são estatisticamente significativos para aqueles que residiam nas regiões Sudeste e Sul, quando comparados com os que moravam no Nordeste. Os primeiros gastavam, respectivamente, $\mathrm{R} \$$ 89,14 e R \$ 99,66 a mais em relação aos da Região Nordeste. Em relação ao AFRC, observa-se que os da Região Sul gastavam a mais $\mathrm{R} \$ 110,01$ do que os do Norte; $\mathrm{R} \$ 193,61$ do que do Nordeste e $\mathrm{R} \$ 86,69$ quando comparados com os da Região Sudeste. Já os residentes no Centro-Oeste e Sudeste também gastavam a mais que o Nordeste, $\mathrm{R} \$ 174,22$ e $\mathrm{R} \$ 106,92$, respectivamente. Com isso, observa-se que os gastos com lazer também eram maiores nas regiões Sul e Sudeste, quando comparados com a Região Nordeste, em ambos os arranjos estudados. Tal resultado talvez possa ser explicado pelo fato de os idosos dessa região possuírem as maiores rendas e, assim, gastarem mais com itens supérfluos, além das necessidades primárias. 
Já em relação aos gastos com educação no AFU, só foi possível comparar estatisticamente aqueles que residiam nas regiões Sul e Nordeste; os idosos deste arranjo que residiam no Sul do país gastavam $\mathrm{R} \$ 23,84$ a mais quando comparados aos do Nordeste. Os resultados da comparação entre as outras regiões apresentaram nível de significância superior a 0,05 , permitindo inferir que as médias de gastos com educação no restante das regiões sejam iguais. $\mathrm{O}$ mesmo aconteceu em relação às despesas com educação do AFRC.

Os gastos referentes ao consumo de alimentos em domicílio no AFU não foram estatisticamente significativos. Infere-se, assim, que a média dos gastos para esse arranjo seja igual entre as regiões do país. Já em relação aos gastos com alimento em domicílio, no AFRC foi estatisticamente significativo para a Região Sul, que possuía um gasto a mais de $\mathrm{R} \$ 1.006,55$ em relação ao Norte, e uma diferença de $\mathrm{R} \$ 747,08$ quando comparada com o Nordeste.

O consumo de alimentos fora do domicílio para o AFU mostrou-se significativo para as regiões Sudeste e Nordeste: aqueles que moravam no Sudeste gastavam R $\$ 219,62$ a mais em relação ao Nordeste. Este gasto no AFRC não se apresentou significativo estatisticamente, o que permite supor que o consumo de alimentos fora do domicílio seja igual entre as regiões do país nesse arranjo familiar. Os dados de outras pesquisas ${ }^{15}$ corroboram o resultado encontrado, sendo que o maior percentual gasto com alimentação fora do domicílio entre as famílias brasileiras ocorreu na Região Sudeste (37,2\%), enquanto os menores percentuais ocorreram nas regiões Norte $(21,4 \%)$ e Nordeste $(23,5 \%)$. Em relação ao valor da despesa média mensal familiar com alimentação fora do domicílio, observa-se que o valor na Região Sudeste ( $\mathrm{R} \$$ 172,78), o maior do Brasil, foi mais que o dobro do valor na Região Nordeste ( $\mathrm{R} \$ 81,23)$, o menor valor do país. Esses resultados, provavelmente, se devem ao fato de a maioria dos idosos residentes no Nordeste possuir renda baixa (faixa de renda $\mathrm{D}$ e E), o que marca ainda mais a desigualdade entre as regiões do país.
Em relação aos gastos com transporte, observa-se que o AFU da Região Sul possuía um gasto de $R \$ 289,75$ a mais em relação aos que residiam no Nordeste; e os da região CentroOeste tinham um gasto de $\mathrm{R} \$ 421,71$ e $\mathrm{R} \$ 340,66$ a mais do que os das regiões Nordeste e Sudeste, respectivamente. O AFRC da Região Sul possuía um gasto de $\mathrm{R} \$ 726,49$ e $\mathrm{R} \$ 885,03$ a mais em relação aos das regiões Norte e Nordeste, respectivamente, e os da região Sudeste ( $\mathrm{R} \$$ 719,56) e Centro-Oeste (R $\$ 704,13)$ também possuíam um gasto a mais quando comparados com os do Nordeste.

Verifica-se, então, que ambos os arranjos, nas regiões Sul e Centro-Oeste, possuíam maiores gastos com transporte quando comparados com os do Nordeste do país, uma vez que eles possuíam as maiores rendas, ao contrário dos que residiam no Nordeste. Nesta região, a maioria possui renda baixa e muitos estão entre as faixas $\mathrm{D}$ e E, o que faz com que tenham que andar a pé ou de bicicleta, ou às vezes, os idosos fazem uso do direito que possuem em relação à gratuidade do transporte coletivo. Estes dados vêm ao encontro de outras pesquisas que trazem a média nacional, ${ }^{15} \mathrm{em}$ que as regiões Sul $(21,9 \%)$ e Centro-Oeste $(21,2 \%)$ registraram participações de transporte mais altas que a média nacional nas despesas de consumo. A Região Norte apresentou o menor percentual para este grupo $(16,5 \%)$.

As despesas com fumo e produtos de higiene e cuidados pessoais não foram estatisticamente significativas entre as regiões do país para os arranjos familiares, inferindo-se que a diferença média do valor gasto com estes itens seja igual entre as regiões do país.

Já no que se refere aos gastos com assistência à saúde, observa-se que os AFUs das regiões Sudeste e Sul gastavam mais quando comparados com os das regiões Norte e Nordeste, sendo a diferença média dos gastos $\mathrm{R} \$ 1.020,59$ e $\mathrm{R} \$ 659,85$, e $\mathrm{R} \$$ $1.186,54$ e $\mathrm{R} \$ 825,80$, respectivamente. Os idosos do Centro-Oeste gastavam $\mathrm{R} \$ 631,03$ a mais em relação aos da Região Norte. Quanto aos gastos com assistência à saúde do AFRC, observa-se que 
os residentes no Sudeste consumiam mais do que os das regiões Norte ( $\mathrm{R} \$ 1.038,38)$, Nordeste ( $\mathrm{R} \$$ $928,09)$ e Sul (R \$ 499,72), enquanto que os que moravam no Centro-Oeste gastavam $\mathrm{R} \$ 473,87$ a mais que os da Região Nordeste. É notório que os idosos do AFU da Região Sul e os do AFRC da Região Sudeste do país possuíam gasto maior com assistência à saúde quando comparados com os das regiões Norte e Nordeste. Estes dados vêm ao encontro de outras pesquisas, ${ }^{15}$ que mostram que para as grandes regiões do país existem comportamentos bastante distintos dos valores médios gastos pelas famílias com assistência à saúde, quando avaliados em relação à despesa total de consumo médio mensal.

No que se refere aos gastos com vestuário, quando se comparam os idosos do AFU da Região Nordeste com Sudeste e Sul, os dados se mostraram estatisticamente significativos, sendo que essas regiões gastavam $\mathrm{R} \$ 102,19$ e $\mathrm{R} \$ 130,96$ a mais em relação ao Nordeste. Observa-se que o AFRC da Região Sul gastava a mais R $\$ 195,13, \mathrm{R} \$$ $238,33, \mathrm{R} \$ 128,42$ e $\mathrm{R} \$ 155,74$, respectivamente, em relação aos que residiam nas regiões Norte, Nordeste, Sudeste e Centro-Oeste. No entanto, em ambos os arranjos familiares, a Região Sul é a que mais apresentou gastos com vestuário, quando comparada às outras regiões do país. Os dados diferem dos resultados de outras pesquisas nacionais, ${ }^{15,22}$ que mostram que o maior resultado relativo de despesas com vestuário entre as famílias brasileiras foi verificado na Região Norte, e o menor, na Sudeste, sendo que a Região Centro-Oeste apresentou participação abaixo da média nacional.

Assim sendo, os dados encontrados nos arranjos familiares em estudo se diferenciam quando comparados com os dados nacionais, uma vez que as diferenças de gastos com vestuário nas famílias podem sofrer alterações devido ao próprio estágio do ciclo de vida familiar em que se encontram, visto que a presença de crianças, por exemplo, faz com que esses gastos tenham peso maior nas despesas, uma vez que eles vão crescendo e tendo a necessidade de trocas, o que não acontece no caso dos domicílios que possuem apenas idosos.

Com base nas análises realizadas, foi possível inferir que o AFRC é o que mais apresenta gastos com as categorias de despesas descritas anteriormente, e apesar de os dados não serem estatisticamente significativos entre todas as regiões para todas as despesas, é plausível afirmar que os idosos dos arranjos analisados que residiam na Região Sul foram os que apresentaram os maiores gastos em relação às categorias de despesas, sobretudo quando comparados aos residentes no Nordeste do país. Isso talvez aconteça porque os idosos residentes no Nordeste possuem as menores rendas e, consequentemente, o menor poder de consumo. Assim, os resultados encontrados corroboram os encontrados por pesquisas nacionais, ${ }^{15,23}$ que afirmam que as famílias, independentemente do arranjo familiar, residentes na Região Sudeste, são as que mantêm a liderança no ranking do consumo nacional, ao contrário da Região Nordeste, que apresenta o menor valor de despesa média no país.

Acredita-se que este estudo apresenta importantes contribuições para a discussão do consumo por idosos nos dois arranjos estudados, mas faz-se necessária a realização de estudos mais aprofundados sobre as questões relativas ao idoso brasileiro, principalmente considerandose suas relações na família e na sociedade, bem como em outros arranjos familiares.

Deve-se também considerar em estudos futuros a utilização dessa metodologia para análise histórica e comparativa dos bens e serviços consumidos entre os diversos arranjos familiares nos quais os idosos estão inseridos, o que permitirá obter estimativas consistentes e inéditas para o Brasil a respeito do vetor de consumo para esse segmento. Embora tenha sido uma limitação para a discussão dos resultados, a pesquisa realizada torna-se mais relevante devido à falta de materiais bibliográficos que tratem do assunto voltado para o público idoso nos diferentes arranjos familiares, como forma de comparar os estudos. 


\section{CONCLUSÃO}

Diante da realização deste estudo, constatouse que o arranjo familiar residindo com $o$ cônjuge apresentou os maiores gastos com habitação, despesas diversas, lazer, transporte, alimentação em domicílio, fumo, produtos de higiene e cuidados pessoais, assistência à saúde e vestuário, talvez pela própria composição familiar. É possível afirmar ainda que, em ambos os arranjos familiares estudados, os que residiam na Região Sul são os que apresentam os maiores gastos, principalmente quando se comparam com aqueles residentes no Nordeste do país, uma

\section{REFERÊNCIAS}

1. Osório AR, Pinto FC. As pessoas idosas: contexto social e intervenção educativa. Lisboa: Horizontes Pedagógicos; 2007.

2. Guimarães JRS. Envelhecimento populacional e oportunidades de negócios: o potencial mercado da população idosa. In: Associação Brasileira de Estudos Populacionais. Encontro Nacional de Estudos Populacionais: Anais do $15^{\circ}$ Encontro Nacional de Estudos Populacionais; $18-22$ set 2006; Caxambu, MG. Caxambu: ABEP; 2006. p. 1-16

3. De Barros RP, Carvalho C. Nota Técnica sobre a recente queda da desigualdade de renda no Brasil. In: De Barros RP, Foguel MN, Ulyssea G, organizadores. Desigualdade de renda no Brasil: uma análise da queda recente. Vol. 1. Brasília: IPEA; 2006. p. 15-85.

4. Carvalho AA. Padrão de consumo de arranjos familiares e das pessoas sozinhas no Brasil: uma análise por gênero e estratos econômicos [dissertação]. Rio de Janeiro: Escola Nacional de Ciências Estatísticas, Instituto Brasileiro de Geografia e Estatística; 2010.

5. Furbino Z, Castro M. Crescimento da renda leva idosos à compra. Estado de Minas [Internet]. 03 mai 2011 [Acesso em 03 mai 2012]. Disponível em: http:// www.em.com.br/app/noticia/economia/2011/03/20/ internas_econo mia,216341/crescimento-da-rendaleva-idosos-a-compra.shtml.

6. Sievert M, Taíse JV. Nova geração de idosos: um consumidor a ser conquistado. In: Conferência Brasileira de Comunicação e Saúde: Anais da 10ª Conferência Brasileira de Comunicação e Saúde; 26 nov 2007; São Paulo. São Paulo: ComSaúde; 2007. p. 1-13. vez que estes últimos são os que apresentaram as menores taxas de renda. Logo, constata-se que a desigualdade na distribuição da renda no país é um fator que influencia no consumo de bens e serviços, uma vez que com a melhoria da renda, os idosos possuem maior poder de compra.

No entanto, a sociedade ainda não está preparada para atender totalmente às necessidades desse segmento. Assim, entender as relações de consumo desse segmento é extremamente relevante, para que os bens e serviços oferecidos proporcionem satisfação e melhoria da qualidade de vida dos idosos.
7. Marino MRGB, Sampaio CA. Brasil idoso: desafios para o consumo. Ident Cient 2013;4(1):22-40.

8. Ventura R. Mudanças no Perfil do Consumo no Brasil: principais tendências nos próximos 20 Anos [Internet]. Rio de Janeiro: Macroplan; 2010 [Acesso em 20 mai 2012]. Disponível: http://www.macroplan.com.br/ Documentos/ArtigoMacroplan2010817182941.pdf

9. Solomon MR. O comportamento do consumidor: comprando, possuindo e sendo. 5. ed. Porto Alegre: Bookman; 2002.

10. Teixeira SM, Rodrigues VS. Modelos de família entre idosos: famílias restritas ou extensas? Rev Bras Geriatr Gerontol 2009;12(2):239-54.

11. Camarano AA, El Ghaouri SK. Famílias com idosos: ninhos vazios? In: Associação Brasileira de Estudos Populacionais. Encontro Nacional de Estudos Populacionais: Anais do $13^{\circ}$ Encontro Nacional de Estudos Populacionais; 4-8 nov 2002; Ouro Preto, MG. Ouro Preto: ABEP; 2002. p. 1-27.

12. Santos IT, Dias CMSB. Homem idoso: vivência de papéis desempenhados ao longo do ciclo vital da família. Aletheia 2008;(27):98-110.

13. Wilmoth J. Arranjos de vida de idosos nos Estados Unidos. Sociologias 2004;4(7):136-55.

14. Instituto Brasileiro de Geografia e Estatística. Pesquisa de orçamentos familiares 2008-2009 [Internet]. Rio de Janeiro: IBGE. Perfil das despesas no Brasil: indicadores selecionados. Microdados; [acesso em 02 mai 2012]. Disponível em: http://www.ibge.gov. br/home/estatistica/populacao/condicaodevida/ pof/2008_2009_perfil_despesas/microdados.shtm 
15. Instituto Brasileiro de Geografia e Estatística. Pesquisa de Orçamentos Familiares 2008-2009: despesas, rendimentos e condições de vida. Rio de Janeiro: IBGE; 2010.

16. Brasil. Ministério da Saúde. Estatuto do idoso. Brasília (DF): Ministério da Saúde; 2003.

17. Hair JF Junior, Anderson RE, Tatham RL, Black WC. Análise multivariada de dados. Sant'Anna AS, Chaves Neto A, tradutores. 5. ed. Porto Alegre: Bookman; 2005.

18. Triola MF. Introdução à estatística. Rio de Janeiro: LTC; 2011.

19. Bruni AL. Estatística aplicada à gestão empresarial. São Paulo: Atlas; 2007.

20. Bertuzzi D, Paskulin LGM, Moraes EP. Arranjos e rede de apoio familiar de idosos que vivem em uma área rural. Texto \& Contexto Enferm 2012;21(1):158-66.
21. Somchinda A, Fernandes FC. Saúde e qualidade de vida na terceira idade: uma introspecção dos idosos institucionalizados [monografia]. Brasília: Associação Brasileira de Odontologia; 2003.

22. Serviço Brasileiro de Apoio às Micro e Pequenas Empresas. Vestuário: Tendências de Consumo [Internet]. Paraná: SEBRAE; 2010 [Acesso em 05 abr 2013]. Disponível em URL: http://portal2.pr.sebrae.com.br/StaticFile/ InteligenciaCompetitiva/docs/Vestu $\% \mathrm{C} 3 \% \mathrm{~A} 1$ rio/ Tend $\%$ C3\%AAncias $\% 20$ de $\% 20$ Consumo/ Tend $\%$ C3\%AAncias $\% 20 \mathrm{de} \% 20$ Consumo.pdf.

23. IPC Marketing: Índice de Potencial de Consumo. O consumo dos brasileiros ultrapassará a marca dos R \$ 2,7 trilhões, em 2012 [Internet]. São Paulo: IPC Marketing; c2012 [acesso em 12 mar 2012]. 17 p. Disponível em: http://www.ipcbr.com/downpress/ IPCMaps2012_Release.pdf. 